\title{
Correction to Synthesis and Characterization of Thermosetting Furan-Based Epoxy Systems
}

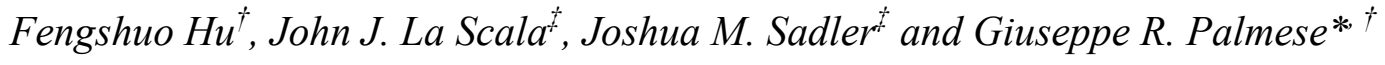 \\ $\dagger$ Department of Chemical \& Biological Engineering, Drexel University, Philadelphia, PA 19104, USA \\ ${ }^{\ddagger}$ Army Research Labs, 4600 Deer Creek Loop, Aberdeen Proving Grounds, MD 21005-5069, USA
}

Macromolecules, 2014, 47 (10), 3332-3342. DOI: 10.1021/ma500687t

KEYWORDS: renewable materials, epoxy resins, thermo-mechanical properties

\begin{abstract}
Renewable alternatives to petroleum-based thermosetting polymers have drawn significant attention due to potential positive economic and ecological impact. New materials should mimic the rigid, phenylic structure of incumbent high-performance thermoset monomers. Furans derived from cellulose and hemicellulose are promising candidates for phenyl replacement. The synthesis of furan-based diepoxies is challenging, and direct property comparisons of thermosets prepared using furanyl and phenyl-based epoxy monomer analogues are required. In this work, analogous furanyl-based and phenyl-based diepoxy monomers were synthesized, and thermosets were prepared using amine curing agents. A structure-property study showed that furan-based polymers possess lower $\mathrm{T}_{\mathrm{g}}\left(\Delta=29^{\circ} \mathrm{C}\right)$ but improved glassy modulus $(\Delta=0.6 \mathrm{GPa})$ relative to
\end{abstract}


their phenylic analogues. The furan ring has thus been demonstrated to be a viable building block for renewable high-performance epoxies, with potential for application in other thermosetting polymers.

\section{INTRODUCTION}

Thermosetting polymers are used extensively for applications in the aerospace, automotive, insulation, electronics and sporting goods industries. ${ }^{1}$ Generally, they possess excellent thermal and mechanical properties as a result of the formation of a cross-linked network when cured. ${ }^{2}$ Epoxy resins are among the most used thermosetting materials because of their unique properties. $^{3}$

Most thermosetting resins are produced from petroleum feedstocks. Recently, the increasing price of fossil fuels and the demand for protecting health and environment have raised interest in manufacturing polymeric materials from renewable resources. ${ }^{2 \mathrm{a}, 4}$ Bio-based resources have the potential to be used for preparing thermosets with performance comparable to petroleum-based systems. ${ }^{5}$ There are numerous biomass sources that have been studied as feedstocks for thermosets. These include plant oils, ${ }^{6}$ cellulose,${ }^{7}$ hemicellulose,${ }^{2 a, 8} \operatorname{lignin}^{9}{ }^{9} \operatorname{starch}^{10}$ and chitin. $^{11}$ Such materials can be transformed to chemicals with specific building blocks that can be converted to monomers used for polymeric materials. Some examples of these building blocks are (i) fatty acids from triglycerides, ${ }^{6}$ (ii) isosorbide from hemicellulose, ${ }^{2 a}, 8$ (iii) phenolic derivatives from lignin, ${ }^{9}$ and (iv) furanyl structures from cellulose and hemicellulose. ${ }^{7}$ Triglyceride-based materials are comprised of aliphatic chains that inherently do not possess the strength and rigidity required for most thermosetting applications. Therefore, complex chemistries are needed to improve properties of materials based on triglycerides. ${ }^{12}$ Isosorbide is reputed to be nontoxic and rigid, however, isosorbide-derived epoxy resins, as well as the 
resulting polymer networks, suffer from relatively high hydrophilicity. ${ }^{13}$ Even though phenolic derivatives from lignin are considered important thermosetting materials due to their aromatic characteristics, their utilization is greatly limited by the challenge of breaking lignin down into useful chemicals. ${ }^{14}$ Furanyl building blocks are considered a promising alternative to petroleum based phenyl building blocks in commercial thermosetting resins because of their aromatic characteristics and feasible availability. ${ }^{15}$ Furanyl chemicals can be produced from existing biomass sources; for example, cellulose, the most abundant compound in wood, can be chemically and bacterially degraded into hexose and converted into hydroxymethylfurfural (HMF), a potential precursor for thermosetting resins. ${ }^{7}$ Hemicellulose can be degraded into pentose and converted into furfuryl alcohol, making it also possible to be used as a bio-based resource. $^{2 \mathrm{a}, 8}$

Furfurylamine $(\mathrm{FA})^{16}$ and furfuryl glycidyl ether $(\mathrm{FGE})^{17}$ are commercial furanyl chemicals that could have applications in epoxy resins. However, these monomers do not provide the ability to crosslink and therefore are generally used as network modifiers, where furan rings become side groups of the polymer network. Generally, high-performance thermosetting systems are based on multifunctional epoxy and amine monomers with ring structures that build directly into the cured polymer networks. ${ }^{18}$ For example, DGEBA (diglycidyl ether of bisphenol A) contains two epoxy functional groups linked by multiple aromatic rings on its main chain. This epoxy is often cured using diamine curing agents such as $4,4^{\prime}$-methylene biscyclohexanamine $(\mathrm{PACM})^{19}$ and diethyl toluene diamine (EPIKURE W) $)^{20}$ which results in crosslinked structures with high thermo-mechanical performance.

There have been limited reports of multifunctional furanyl based epoxy resins. ${ }^{15 a, 15 b}$ Cho et al. recently reported two furan-based di-epoxies, BOF (a mono-furan di-epoxide, in Figure 1) and 
bFdE (a bis-furan di-epoxide, in Figure 1). ${ }^{15 a}$ The materials developed by Cho et al. were photocured cationically using IRGACURE 250 and triphenylsulfonium hexafluoroantimonate salt initiators and the adhesive strengths of these materials were tested using a lap-shear configuration. Fundamental properties such as $\mathrm{T}_{\mathrm{g}}$ and tensile modulus were not reported. Moreover, a comparison was not made with petroleum based phenyl analogs. It should also be noticed that cationic cure of epoxies proceeds via a chain mechanism that results in vastly different network structures compared to step-growth epoxy-amine polymerization. The synthesis of BOF was also reported by Jeong et al., however, BOF was only utilized as an intermediate for which thermo-mechanical properties were not investigated. ${ }^{15 b}$ Thus, there are no reports of the properties of di-epoxies based on furanyl building blocks. Moreover, it is crucial to fundamentally understand how furanyl building blocks affect thermo-mechanical properties of epoxy resins compared to phenyl building blocks in order to better design furan-based thermosets with the goal of replacing petroleum-based systems. No direct comparison between furanyl and phenyl based epoxy resins has been shown in literature. In this work, we seek to understand structure-property relationships of furan-based di-epoxies relative to those of phenylbased di-epoxies.

While there have been no reports on the syntheses and properties of epoxy-amine networks based on furanyl building blocks (note that we exclude works with FA and FGE for the reasons discussed earlier), there are numerous examples in the literature of bio-based epoxy systems and their properties that provide general points of comparison. Table 1 summarizes these works in three categories: lignin, cellulose/hemicellulose and plant oil systems. The table contains works where thermo-mechanical properties of the bio-based systems were obtained and where comparisons were made to the standard DGEBA based systems. Beginning with lignin derived 
structures as examples, Nouailhas et al. reported a catechin-based epoxy monomer with similar performance to DGEBA prepared with the same curing agent. ${ }^{21}$ Aouf et al. reported a gallic acid derived epoxy resin that displayed a higher $\mathrm{T}_{\mathrm{g}}$ compared to DGEBA when cured with isophorone diamine (IPD). ${ }^{22}$ Ochi et al. synthesized a vanillin derived epoxy resin (BMPTU) with a similar structure to DGEBA that showed comparable $\mathrm{T}_{\mathrm{g}}$ and storage modulus to DGEBA when cured with 4,4'-diaminodiphenylmethane (DDM). ${ }^{23}$ For cellulose/hemicellulose derived structures, Sachinvala et al. prepared a mixture of epoxy allyl sucroses (EAS) with variable epoxy groups per monomer. ${ }^{24}$ This resin possessed a much lower $\mathrm{T}_{\mathrm{g}}$ value relative to DGEBA when cured with diethylenetriamine (DETA). East et al. recently explored the preparation of an isosorbide-based epoxy resin. ${ }^{25}$ Much lower $T_{g} s$ compared to DGEBA when cured with an aliphatic triamine (Jeffamine T403) and DDM were reported. Łukaszczyk et al. reported a less pure isosorbide based epoxy resin with an epoxy number of $0.44 \mathrm{~mol}$ per $100 \mathrm{~g}$ which was cured using triethylenetetramine (TETA) and IPD that possessed $\mathrm{T}_{\mathrm{gS}} 70{ }^{\circ} \mathrm{C}$ lower than DGEBA. ${ }^{13}$ Chrysanthos et al. recently synthesized two isosorbide-based epoxy resins, one containing the pure epoxy monomer (DGEDAS $)_{0}$ ) and the other consisting of various oligomeric species $\left(\right.$ DGEDAS $\left._{\mathrm{n}}\right) .^{26} \mathrm{~T}_{\mathrm{g}}$ values of the resulting thermosets prepared with IPD were consistently lower than analogous DGEBA systems. For the category of plant oil derived structures, Earls et al. reported the thermo-mechanical properties of several glycerides containing terminal/nonterminal epoxy groups on aliphatic chains with varying chain lengths. ${ }^{27}$ The resulting thermosets cured with DDM possessed $\mathrm{T}_{\mathrm{g}}$ values of $48-133{ }^{\circ} \mathrm{C}$ much lower than DGEBA-DDM system and also relatively lower flexural moduli. Lligadas et al. prepared two fatty acid derived epoxy resins, epoxidized 10-undecenoyl triglyceride (UDTGE) and epoxidized methyl 3,4,5-tris(10- 
undecenoyloxy)benzoate (UDBME), that possessed similar $\mathrm{T}_{\mathrm{g}}$ values $\left(\sim 70^{\circ} \mathrm{C}\right)$ when cured with DDM, ${ }^{12 \mathrm{~b}}$ both of which were significantly lower than DGEBA-DDM system $\left(184{ }^{\circ} \mathrm{C}\right) .^{27}$

Table 1. Thermo-mechanical properties of several bio-based epoxy resins reported in the literature

\begin{tabular}{|c|c|c|c|c|}
\hline $\begin{array}{l}\text { Bio-based } \\
\text { Epoxy Resin }\end{array}$ & Curing Process & Properties & Comparison & Ref \\
\hline \multicolumn{5}{|l|}{ Lignin } \\
\hline $\mathrm{GEC}^{a}$ & $\begin{array}{l}\text { Composition ( } 1) \\
75 \mathrm{wt} \% \text { DGEBA } / 25 \mathrm{wt} \% \mathrm{GEC} \text {, } \\
\text { composition }(2) \\
50 \mathrm{wt} \% \text { DGEBA } / 50 \mathrm{wt} \% \mathrm{GEC} \text { and } \\
\text { DGEBA were stoichiometrically } \\
\text { cured with Epamine PC } 19^{b} \text { at } 60 \\
{ }^{\circ} \mathrm{C} \text { for } 24 \mathrm{~h} \text {. }\end{array}$ & $\begin{array}{l}\text { (1): } \sim 55^{\circ} \mathrm{C}^{c} \\
2.46 \mathrm{GPa}^{d} \\
\text { (2): } \sim 50{ }^{\circ} \mathrm{C}^{c} \\
2.40 \mathrm{GPa}^{d}\end{array}$ & $\begin{array}{l}\text { DGEBA } \\
\sim 55^{\circ} \mathrm{C}^{c}, 2.81 \\
\mathrm{GPa}^{d}\end{array}$ & $\begin{array}{l}\text { Nouailhas et } \\
\text { al. }{ }^{21}\end{array}$ \\
\hline $\mathrm{GEGA}^{e}$ & $\begin{array}{l}\text { GEGA and DGEBA were } \\
\text { stoichiometrically cured with IPD } \\
\text { at } 90^{\circ} \mathrm{C} \text { for } 0.5 \mathrm{~h} \text { and } 200^{\circ} \mathrm{C} \text { for } \\
2 \mathrm{~h} .\end{array}$ & $233^{\circ} \mathrm{C}^{f}$ & $\begin{array}{l}\text { DGEBA } \\
160^{\circ} \mathrm{C}^{f}\end{array}$ & Aouf et al. ${ }^{22}$ \\
\hline BMPTU $^{g}$ & $\begin{array}{l}\text { BMPTU was cured with DDM at } \\
180^{\circ} \mathrm{C} \text { for } 2 \mathrm{~h} \text { and } 200^{\circ} \mathrm{C} \text { for } 4 \mathrm{~h} \text {; } \\
\text { DGEBA was cure with DDM at } \\
80^{\circ} \mathrm{C} \text { for } 2 \mathrm{~h} \text { and } 180^{\circ} \mathrm{C} \text { for } 6 \mathrm{~h} \text {. }\end{array}$ & $167^{\circ} \mathrm{C}^{h}$ & $\begin{array}{l}\text { DGEBA } \\
174{ }^{\circ} \mathrm{C}^{h}\end{array}$ & $\begin{array}{l}\text { Ochi et al. }{ }^{23} \text {; } \\
\text { Koike et } \\
\text { al. }^{28}\end{array}$ \\
\hline \multicolumn{5}{|c|}{ Cellulose/Hemicellulose } \\
\hline $\begin{array}{l}\operatorname{EAS} 3.7^{i} \\
\operatorname{EAS} 3.2^{j} \\
\operatorname{EAS} 1.6^{k}\end{array}$ & $\begin{array}{l}\text { EAS3.7, EAS3.2 and EAS } 1.6 \\
\text { were stoichiometrically cured } \\
\text { with DETA from } 25 \text { to } 230{ }^{\circ} \mathrm{C} .^{l}\end{array}$ & $\begin{array}{l}\text { EAS3.7: } \\
72{ }^{\circ} \mathrm{C}^{m} \\
\text { EAS3.2: } \\
62{ }^{\circ} \mathrm{C}^{m} \\
\text { EAS } 1.6 \text { : } \\
16{ }^{\circ} \mathrm{C}^{m}\end{array}$ & $\begin{array}{l}\text { DGEBA } \\
134{ }^{\circ} \mathrm{C}^{m}\end{array}$ & $\begin{array}{l}\text { Sachinvala } \\
\text { et al. }\end{array}$ \\
\hline $\begin{array}{l}\text { Isosorbide } \\
\text { epoxy }\end{array}$ & $\begin{array}{l}\text { Isosorbide epoxy was } \\
\text { stoichiometrically cured with } \\
\text { Jeffamine T } 403 \text { at } 100{ }^{\circ} \mathrm{C} \text { for } 4 \mathrm{~h} \text {; } \\
\text { with DDM at } 80^{\circ} \mathrm{C} \text { for } 2 \mathrm{~h}, 120\end{array}$ & $\begin{array}{l}\text { T403: } 48^{\circ} \mathrm{C}^{n} \\
\text { DDM: } 89^{\circ} \mathrm{C}^{n}\end{array}$ & $\begin{array}{l}\text { DGEBA } \\
\text { T403: } 93{ }^{\circ} \mathrm{C}\end{array}$ & $\begin{array}{l}\text { East et al. }{ }^{25} \text {; } \\
\text { Fenouillot et } \\
\text { al. }^{29} \text {; } \\
\text { Morgan et }\end{array}$ \\
\hline
\end{tabular}




\begin{tabular}{|c|c|c|c|c|}
\hline & ${ }^{\circ} \mathrm{C}$ for $16 \mathrm{~h}$ and $150{ }^{\circ} \mathrm{C}$ for $2 \mathrm{~h}$. & & DDM: $174{ }^{\circ} \mathrm{C}$ & $\begin{array}{l}\text { al. }^{30} \text {; Ochi et } \\
{ }^{23}{ }^{3}\end{array}$ \\
\hline IS-EPO $^{o}$ & $\begin{array}{l}\text { IS-EPO and DGEBA were } \\
\text { stoichiometrically cured with } \\
\text { TETA at } 25^{\circ} \mathrm{C} \text { for } 24 \mathrm{~h} \text { and } 80 \\
{ }^{\circ} \mathrm{C} \text { for } 24 \mathrm{~h} \text {; with IPD at the same } \\
\text { curing condition. }\end{array}$ & $\begin{array}{l}\text { TETA: } 49 \mathrm{C}^{p}, \\
\text { 5.5 } \mathrm{GPa}^{q} \\
\text { IPD: } 73{ }^{\circ} \mathrm{C}^{p} \\
\text { 14.6 } \mathrm{GPa}^{q}\end{array}$ & $\begin{array}{l}\text { DGEBA } \\
\text { TETA: } 116^{\circ} \mathrm{C}^{p} \\
, 8.3 \mathrm{GPa}^{q} ; \\
\text { IPD: } 141^{\circ}{ }^{p}{ }^{p} \\
10.4 \mathrm{GPa}^{q}\end{array}$ & $\begin{array}{l}\text { Łukaszczyk } \\
\text { et al. }{ }^{13}\end{array}$ \\
\hline $\begin{array}{l}\operatorname{DGEDAS}_{0}{ }^{r} \\
\operatorname{DGEDAS}_{\mathrm{n}}{ }^{s}\end{array}$ & $\begin{array}{l}\text { DGEDAS }_{0}, \text { DGEDAS }_{\mathrm{n}} \text { and } \\
\text { DGEBA were stoichiometrically } \\
\text { cured with IPD at } 80^{\circ} \mathrm{C} \text { for } 1 \mathrm{~h} \\
\text { and } 180^{\circ} \mathrm{C} \text { for } 2 \mathrm{~h} .\end{array}$ & $\begin{array}{l}\text { DGEDAS }_{0}: \\
112^{\circ} \mathrm{C}^{t} \\
\\
\operatorname{DGEDAS}_{\mathrm{n}} \\
96^{\circ} \mathrm{C}^{t}\end{array}$ & $\begin{array}{l}\text { DGEBA } \\
155^{\circ} \mathrm{C}^{t}\end{array}$ & $\begin{array}{l}\text { Chrysanthos } \\
\text { et al. }{ }^{26}\end{array}$ \\
\hline Plant oil & & & & \\
\hline $\begin{array}{l}\text { Epoxidized } \\
\text { triglyceride }\end{array}$ & $\begin{array}{l}\mathbf{1 , 2 a}, \mathbf{2 b}, \mathbf{2 c}, \mathbf{2 d} \text { and DGEBA } \\
\text { were stoichiometrically cured } \\
\text { with DDM. Cure temperature was } \\
\text { increased by } 25^{\circ} \mathrm{C} \text { per } 2 \mathrm{~h} \text { from } \\
\text { initial temperature upon reaching } \\
\text { final temperature with an } \\
\text { additional } 2 \mathrm{~h}: 120 \text { to } 200^{\circ} \mathrm{C} \text { for } \\
\mathbf{1} ; 120 \text { to } 180^{\circ} \mathrm{C} \text { for } \mathbf{2 a} \text { and } \mathbf{2 c} ; 90 \\
\text { to } 180^{\circ} \mathrm{C} \text { for } \mathbf{2 b} ; 120^{\circ} \mathrm{C} \text { for } \mathbf{2 d} \text {. } \\
120 \text { to } 180^{\circ} \mathrm{C} \text { for DGEBA. }\end{array}$ & $\begin{array}{l}\text { 1: } 54{ }^{\circ} \mathrm{C}^{v}, \\
1.5 \mathrm{GPa}^{w} ; \\
\text { 2a: } 56^{\circ} \mathrm{C}^{v}, \\
1.1 \mathrm{GPa}^{w} ; \\
\text { 2b: } 48^{\circ} \mathrm{C}^{v}, \\
1.1 \mathrm{GPa}^{w} ; \\
\text { 2c: } 68^{\circ} \mathrm{C}^{v}, \\
1.9 \mathrm{GPa}^{w} ; \\
\text { 2d: } 133^{\circ} \mathrm{C}^{v}, \\
3.2 \mathrm{GPa}^{w}\end{array}$ & $\begin{array}{l}\text { DGEBA } \\
184{ }^{\circ} \mathrm{C}^{v} \\
2.4 \mathrm{GPa}^{w}\end{array}$ & Earls et al. ${ }^{27}$ \\
\hline $\begin{array}{l}\text { UDTGE }^{x} \\
\text { UDBME }^{y}\end{array}$ & $\begin{array}{l}\text { UDTGE was stoichiometrically } \\
\text { cured with DDM at } 100^{\circ} \mathrm{C} \text { for } \\
1.5 \mathrm{~h} \text { and } 140^{\circ} \mathrm{C} \text { for } 1 \mathrm{~h} \text {. } \\
\text { UDBME was stoichiometrically } \\
\text { cured with DDM at } 90^{\circ} \mathrm{C} \text { for } 1.5 \\
\mathrm{~h} \text { and } 160^{\circ} \mathrm{C} \text { for } 1 \mathrm{~h} \text {. }\end{array}$ & $\begin{array}{l}\text { UDTGE: } \\
63^{\circ} \mathrm{C}^{z} \\
\text { UDBME: } \\
74^{\circ} \mathrm{C}^{z}\end{array}$ & $\begin{array}{l}\text { DGEBA } \\
174{ }^{\circ} \mathrm{C}\end{array}$ & $\begin{array}{l}\text { Lligadas et } \\
\text { al. }^{12 b} \\
\text { Ochi et al. }\end{array}$ \\
\hline
\end{tabular}

${ }^{a}$ Glycidyl ether of catechin, $80 \%$ purity.

${ }^{b} \mathrm{~A}$ mixture of BPA-epichlorohydrin polymer, benzyl alcohol, 1,3-bis(aminomethyl)benzene and 3-aminomethyl-3,5,5-trimethylcyclohexylamine.

${ }^{c} \mathrm{~T}_{\mathrm{g}}$ assigned as the temperature at the maximum of loss factor by DMA from 25 to $120{ }^{\circ} \mathrm{C}$ at 3 ${ }^{\circ} \mathrm{C} / \mathrm{min}$ and a frequency of $5 \mathrm{~Hz}$.

${ }^{d}$ Storage modulus at $30^{\circ} \mathrm{C}$. 
${ }^{e}$ Glycidyl derivative of gallic acid.

${ }^{f} \mathrm{~T}_{\mathrm{g}}$ assigned as the temperature at the maximum of tan $\delta$ curve by DMA from 30 to $300{ }^{\circ} \mathrm{C}$ at 3 ${ }^{\circ} \mathrm{C} / \mathrm{min}$, a frequency of $1 \mathrm{~Hz}$ and strain at $0.1 \%$.

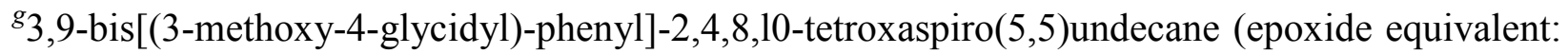
$282 \pm 5)$.

${ }^{h} \mathrm{~T}_{\mathrm{g}}$ assigned as the temperature at the maximum of $\tan \delta$ curve by an inverted, free-oscillation, torsion pendulum (RD-1100AD, Rhesca Co. Ltd.) from -160 to $250{ }^{\circ} \mathrm{C}$ at $0.7^{\circ} \mathrm{C} / \mathrm{min}$ in vacuo.

${ }^{i}$ Epoxy allyl sucroses (3.7 epoxy groups per sucrose).

${ }^{j}$ Epoxy allyl sucroses (3.2 epoxy groups per sucrose).

${ }^{k}$ Epoxy allyl sucroses (1.6 epoxy groups per sucrose).

${ }^{l}$ Cured by heating from 25 to $230{ }^{\circ} \mathrm{C}$ at $5{ }^{\circ} \mathrm{C} / \mathrm{min}$ by DSC with $20-40 \mathrm{mg}$ premixed epoxy-amine samples in open aluminum pans under dry nitrogen.

${ }^{m} \mathrm{~T}_{\mathrm{g}}$ determined at the inflection point of the forward step curve by DSC from -140 to $200{ }^{\circ} \mathrm{C}$ at $10{ }^{\circ} \mathrm{C} / \mathrm{min}$.

${ }^{n} \mathrm{~T}_{\mathrm{g}}$ measured by DSC.

${ }^{o}$ Isosorbide based epoxy resin, epoxy number: $0.44 \mathrm{~mol} / 100 \mathrm{~g}$.

${ }^{p} \mathrm{~T}_{\mathrm{g}}$ measured by DSC from 0 to $250{ }^{\circ} \mathrm{C}$ at $10{ }^{\circ} \mathrm{C} / \mathrm{min}$.

${ }^{q}$ Flexural modulus measured on Zwick 100N5A with extensometer in accordance with the PNEN ISO 178:2006 standard.

${ }^{r}$ The monomer of isosorbide diglycidyl ether, $100 \%$ purity (epoxide equivalent: 143 ).

${ }^{s}$ The oligomer of isosorbide diglycidyl ether (epoxide equivalent: 184).

${ }^{t} \mathrm{~T}_{\mathrm{g}}$ assigned as the temperature at the maximum of tan $\delta$ curve by DMA from -100 to $200{ }^{\circ} \mathrm{C}$ at $3^{\circ}$ $\mathrm{C} / \mathrm{min}$ with a frequency of $1 \mathrm{~Hz}$ and strain at $0.5 \%$ under a nitrogen stream.

${ }^{u}$ Compound 1 was epoxidized linseed oil, compounds $\mathbf{2 a}, \mathbf{2 b}, \mathbf{2 c}$ and $\mathbf{2 d}$ were terminalepoxidized trifunctional triglycerides with different chain lengths.

${ }^{v} \mathrm{~T}_{\mathrm{g}}$ measured by DSC from -50 to $300^{\circ} \mathrm{C}$ at $10^{\circ} \mathrm{C} / \mathrm{min}$.

${ }^{w}$ Flexural modulus determined using ASTM method D-790.

${ }^{x}$ Epoxidized 10-undecenoyl triglyceride, $100 \%$ purity.

${ }^{y}$ Epoxidized methyl 3,4,5-tris(10-undecenoyloxy)benzoate, $100 \%$ purity.

${ }^{z} \mathrm{~T}_{\mathrm{g}}$ assigned as the temperature at the maximum of loss-modulus curve by DMTA from -100 to $150{ }^{\circ} \mathrm{C}$ at $5{ }^{\circ} \mathrm{C} / \mathrm{min}$ and a frequency of $1 \mathrm{~Hz}$. 
Several parameters affect the overall thermo-mechanical properties of epoxy thermosetting polymers. These include cure conditions, extent of reaction, purity, curing agent selection and building block type. The cure conditions, which determine the extent of reaction, are critical to final properties of the epoxy thermosets. Identical epoxy-amine thermosetting systems cured to different degrees possess different thermo-mechanical properties. For example, DGEBA-IPD and DGEBA-DDM systems reported by different researchers in Table 1 show different $T_{\mathrm{g}} \mathrm{s}$. The different $T_{g}$ measurement techniques are a possible reason for this observation, but it should be noted that since most of the literature in Table 1 failed to provide the extent of reaction to indicate the full conversion between epoxy/amine functional groups, the reason for the observed difference is not clear. So, $\mathrm{T}_{\mathrm{g}}$ data presented in the absence of cure conversion data can have significant uncertainties.

The purity of bio-based epoxy resins also has a significant impact on the overall performance. For instance, the isosorbide based epoxy resin reported by Łukaszczyk et al. ${ }^{13}$ was cured with IPD without purification and a $\mathrm{T}_{\mathrm{g}}$ of $73{ }^{\circ} \mathrm{C}$ was observed, whereas the monomer of isosorbide diglycidyl ether with a $100 \%$ purity prepared by Chrysanthos et al. ${ }^{26}$ was cured with the same curing agent and a much higher $\mathrm{T}_{\mathrm{g}}\left(112^{\circ} \mathrm{C}\right)$ was reported.

The curing agent selected is obviously another important factor to affect the properties of epoxy thermosets. DGEBA cured with DDM gives the highest $\mathrm{T}_{\mathrm{g}}\left(184^{\circ} \mathrm{C}\right)^{27}$ when compared to other curing agents: IPD $\left(155^{\circ} \mathrm{C}\right),{ }^{26}$ DETA $\left(134{ }^{\circ} \mathrm{C}\right)^{24}$ and Jeffamine T403 $\left(93^{\circ} \mathrm{C}\right) .{ }^{30}$ The reason is because of the different structural rigidity and functionality of these amine curing agents. This makes it more difficult to compare the properties of bio-based epoxies studied by different research groups. 
Notwithstanding the above discussion concerning factors that influence thermo-mechanical properties of thermosets, generally, due to their aromatic characteristics, lignin and cellulose derived building blocks endow thermosetting epoxy resins with higher thermo-mechanical properties compared to those from plant oils. For example, when cured with DDM, BMPTU, ${ }^{23,28}$ isosorbide based epoxy $y^{25,29}$ and epoxidized linseed oil ${ }^{27}$ possess $\mathrm{T}_{\mathrm{g}}$ values of $167^{\circ} \mathrm{C}, 89^{\circ} \mathrm{C}$ and $54{ }^{\circ} \mathrm{C}$, respectively. However, no direct comparisons exist between resin systems based on phenyl and furanyl building blocks derived from lignin and cellulose, respectively. In order to properly assess the effects on properties related to the selected phenyl and furanyl building blocks, epoxy resins with analogous structures in which only the ring is varied must be compared. Moreover, other factors including cure conditions, extent of reaction, purity and curing agent selection must be kept consistent. Hence, in this work, thermo-mechanical properties of two analogous epoxy resins are investigated and compared. The two mimetic epoxy resin monomers, 2,5-bis[(2-oxiranylmethoxy)methyl]-Furan (BOF) and 2,5-bis[(2oxiranylmethoxy)methyl]-Benzene (BOB), were prepared according to the literature and cured using standard amine curing agents, PACM and EPIKURE W. Thermo-mechanical properties of these analogous systems were evaluated and robust conclusions regarding structure-property relationships associated with the use of furanyl versus phenyl building blocks were drawn supporting the competitiveness of cellulose derived structures for use in thermosetting materials.

\section{EXPERIMENTAL SECTION}

Materials. All reagents and solvents used in this work, including tetrabutylammonium hydrogen sulfate (99+\%), tetrabutylammonium bromide (98+\%), epichlorohydrin (99\%), ethyl acetate (99.8\%), hexane (95\%), sodium hydroxide (98\%), tetrahydrofuran (THF, 99.9\%), silica gel (60Å, 70-230mesh), furfuryl glycidyl ether (FGE, 96\%), 1,4-benzenedimethanol (99\%), 
glacial acetic acid (99.7\%), acetic anhydride (99+\%), crystal violet indicator, perchloric acid $(0.1$ $\mathrm{N}$ solution in glacial acetic acid), methylene chloride (99.8\%) and potassium acid phthalate (99.95\%) were supplied by Sigma-Aldrich, USA; 1,4-Bis(glycidyloxy)benzene (DGEPP, 97+\%) was supplied by Alfa Aesar, USA; 2,5-bis(hydroxymethyl) furan (b-HMF, 98+\%) was supplied by Pennakem, LLC, USA. EPON 828 composed of diglycidyl ether of bisphenol A (DGEBA) and low molecular weight oligomers of DGEBA and EPIKURE $\mathrm{W}$ composed of isomers of diethyl toluene diamine were supplied by Miller-Stephenson chemical company, USA; 4, 4'methylene biscyclohexanamine (PACM, 99+\%) was supplied by Air Products, USA. All chemicals were used as received.

The structures of the epoxy monomers and diamine curing agents used in this work, as well as materials discussed in the introduction, are summarized in Figure 1. A and B are furanyl- and phenyl-based epoxy monomers which have been synthesized; C and D and E are commercial epoxies used with or without $\mathrm{A}$ and $\mathrm{B}$ to prepare a number of thermosets cured by the amine curing agents $\mathrm{F}$ and $\mathrm{G}$ as described throughout this work. $\mathrm{H}$ and I are materials discussed in the introduction. 
A.<smiles>c1cc(COCC2CO2)oc1COCCC1CO1</smiles>

C.

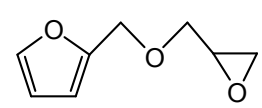

B.

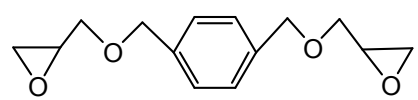

D.

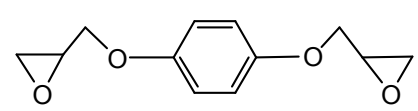

E.

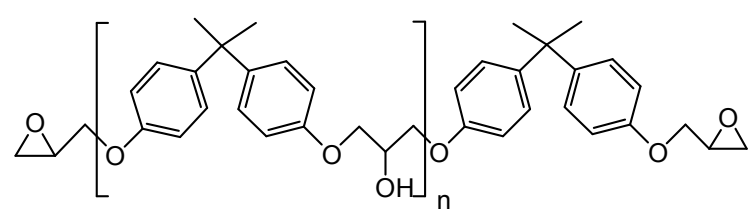

F.<smiles>NC1CCC(CC2CCC(N)CC2)CC1</smiles>

G.

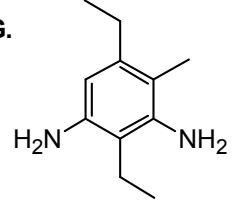

I.

H.

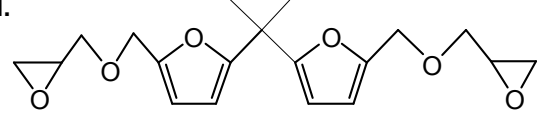

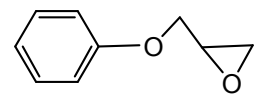
A. 2, 5-bis[(2-oxiranylmethoxy)methyl]-Furan (BOF),
Furan diepoxide in ref $15 \mathrm{a}$ and $15 \mathrm{~b}$;
B. 1, 4-bis[(2-oxiranylmethoxy)methyl]-Benzene (BOB);
C. furfuryl glycidyl ether (FGE);
D. 1,4-Bis(glycidyloxy)benzene (DGEPP);
E. diglycidyl ether of bisphenol A (DGEBA), EPON 828, $n=0.13$;
F. 4, 4'-methylene biscyclohexanamine (PACM);
G. diethyl toluene diamine (EPIKURE W);
H. Bis-furan di-epoxide (bFdE) in ref $15 \mathrm{a}$ and $15 \mathrm{~b}$;
I. Phenyl glycidyl ether (PGE).

Figure 1. Materials used in this work and discussed in the introduction.

Synthesis of 1, 4-bis[(2-oxiranylmethoxy)methyl]-Benzene (BOB). A $1000 \mathrm{~mL}$ threenecked round-bottom flask was equipped with a magnetic stirring bar, a constant-pressure dropping funnel, a thermometer and an inlet for dry nitrogen. Oxygen and moisture in the reactor was replaced with dry nitrogen. Tetrabutylammonium bromide was used as a catalyst. ${ }^{31} 1,4-$ benzenedimethanol (13.8 g, $0.1 \mathrm{~mol})$, tetrabutylammonium bromide (TBAB) $(3.22 \mathrm{~g}, 0.01 \mathrm{~mol})$ and $40 \% \mathrm{w} / \mathrm{w}$ aqueous sodium hydroxide $(250 \mathrm{ml})$ were vigorously stirred in the flask at $50{ }^{\circ} \mathrm{C}$ for 1 hour. Then, the flask was placed into an ice batch for half an hour before epichlorohydrin (73.6 g, $0.8 \mathrm{~mol}$ ) was added dropwise using a constant-pressure dropping funnel over a period of 0.5 hours. The mixture was allowed to react for another 21 hours with vigorous stirring after the 
temperature reached RT. The mixture was then poured into $125 \mathrm{ml}$ ice/water and extracted three times with $50 \mathrm{ml}$ diethyl ether. The combined organic phase was washed with deionized water to neutral $\mathrm{pH}$, dried with anhydrous $\mathrm{MgSO}_{4}$ and concentrated using vacuum. The residue was purified by reduced-pressure distillation to yield $\mathrm{BOB}$ as a colorless liquid. An overall yield of $90 \%$ was obtained $(22.5 \mathrm{~g})$ and the purity was $99 \%$ by ${ }^{1} \mathrm{H}$ NMR.

Synthesis of 2, 5-bis[(2-oxiranylmethoxy)methyl]-Furan (BOF). ${ }^{\mathbf{1 5 b}}$ A $1000 \mathrm{~mL}$ four-necked round-bottom flask was equipped with a constant-pressure dropping funnel, a thermometer, a condenser, an inlet for dry nitrogen and a magnetic stirring bar. The air inside the system was replaced with nitrogen to eliminate oxygen and moisture. Tetrabutylammonium hydrogen sulfate was used as a catalyst. ${ }^{32}$ With continuous stirring, epichlorohydrin $(202.4 \mathrm{~g}, 2.2 \mathrm{~mol})$ and tetrabutylammonium hydrogen sulfate $(4.07 \mathrm{~g}, 0.012 \mathrm{~mol})$ were charged into the flask at $65^{\circ} \mathrm{C}$. 2,5-bis(hydroxymethyl) furan (b-HMF) $(128.05 \mathrm{~g}, 1 \mathrm{~mol})$ was added into the flask dropwise after being melted $\left(\mathrm{T}_{\mathrm{m}}=68^{\circ} \mathrm{C}\right)$. The reaction was allowed to proceed for 4 hours, then the mixture was cooled to $50^{\circ} \mathrm{C}$ and $320 \mathrm{~mL}$ of sodium hydroxide aqueous solution $(50 \% \mathrm{w} / \mathrm{w})$ was added dropwise to complete the intramolecular ring-closing epoxidation reaction. After 2 hours, the mixture was extracted three times with $50 \mathrm{ml}$ diethyl ether. The combined organic phase was washed with deionized water and dried with anhydrous $\mathrm{MgSO}_{4}$. A rotary evaporator was used to remove the solvent, leaving a brown-red liquid residue. Silica gel chromatography with ethyl acetate/hexane (2 to 1 by volume) was used to purify the BOF as a yellow liquid. An overall yield of $60 \%$ was obtained (144 g) and the purity was $99 \%$ by ${ }^{1} \mathrm{H}$ NMR.

Characterization of BOF and BOB. BOF and BOB were characterized by epoxy titration (ASTM D 1652-97), gel permeation chromatography (GPC), Fourier transform infrared 
spectroscopy (FT-IR), ${ }^{1} \mathrm{H}$ NMR, ${ }^{13} \mathrm{C}$ NMR (nuclear magnetic resonance), rheometry and Mass Spectrometry (MS).

Epoxy titration was performed by following ASTM D1652-90, Procedure B ${ }^{33}$ to determine epoxy equivalent weight (EEW) of BOF and BOB. For example, a mixture was prepared with BOF $(0.4 \mathrm{~g})$, methylene chloride $(10 \mathrm{~mL})$, tetraethylammonium bromide solution $(10 \mathrm{~mL}, 0.25$ $\mathrm{g} / \mathrm{mL}$ ) and 8 drops of $0.1 \%$ solution of crystal violet indicator in glacial acetic acid. Titration was conducted using $0.1 \mathrm{~N}$ perchloric acid reagent. The mixture displayed a sharp color change from blue to green and the volume of perchloric acid agent used was recorded. Multiple titrations were conducted.

GPC was used to measure the purity of BOF and BOB. A Waters 515 GPC with two $30 \mathrm{~cm}$ long, $7.5 \mathrm{~mm}$ diameter, $5 \mu \mathrm{m}$ (poly)styrene-divinyl benzene columns (PLgel $5 \mu \mathrm{m}$ MIXED-C column and PLgel $5 \mu \mathrm{m} 50 \AA \AA$ column) in series. Columns were equilibrated and maintained at 45 ${ }^{\circ} \mathrm{C}$ with elution with THF at a rate of $1.0 \mathrm{~mL} / \mathrm{min}$. The column effluent was monitored using two detectors: a Waters 2487 dual absorbance detector operating at 280 and $254 \mathrm{~nm}$, and a Waters 2410 refractive index detector at $25{ }^{\circ} \mathrm{C}$. Samples $(2 \mathrm{mg})$ were dissolved in THF $(1 \mathrm{~mL})$ and filtered before being injected into GPC. The total running time for each sample was 25 minutes with a flow rate of $1 \mathrm{ml} / \mathrm{min}$.

Functional groups of BOF and BOB, such as furanyl, phenyl and epoxy, were identified using a Thermo Nicolet Nexus 870 Fourier transform infrared spectrometer (FT-IR) in absorbance mode. Spectra were recorded with 32 scans at an $8 \mathrm{~cm}^{-1}$ resolution at RT with a deuterated tryglycine sulfate (DTGS) detector in $4000-8000 \mathrm{~cm}^{-1}$ range for near infrared spectra (N-IR) and $650-4000 \mathrm{~cm}^{-1}$ for mid-infrared spectra (M-IR). 
Proton and carbon nuclear magnetic resonance $\left({ }^{1} \mathrm{H}\right.$ NMR and ${ }^{13} \mathrm{C}$ NMR $)$ measurements were used to confirm chemical structures of BOF and BOB. Both ${ }^{1} \mathrm{H}$ NMR and ${ }^{13} \mathrm{C}$ NMR were obtained using a Varian Unity Inova NMR $(500 \mathrm{MHz})$ instrument with spectral window of \pm $2000 \mathrm{~Hz}, 32$ scans for ${ }^{1} \mathrm{H}$ NMR and 5000 scans for ${ }^{13} \mathrm{C}$ NMR at $293 \mathrm{~K}$ and $90^{\circ}$ pulse width.

Monomer viscosity was measured using an AR2000 ex Rheometer (TA instruments) with 40 $\mathrm{mm}$ flat plate configuration using a shear rate range from 0.01 to $1000 \mathrm{~s}^{-1}$, with 10 measurements recorded per decade. Shear stress was measured every $2 \mathrm{~s}$ at each shear rate. Viscosity was reported as the average of three measurements at a shear rate of $1000 \mathrm{~s}^{-1}$.

Mass Spectrometry (MS) was conducted by a Water AutoSpec-Ultima triple sector high resolution mass spectrometer using chemical ionization with methane as the ionizing gas in positive ion mode.

Preparation of cured BOF and BOB polymers. ${ }^{34} 4$, 4'-methylene biscyclohexanamine (PACM) and diethyl toluene diamine (EPIKURE W) were used as curing agents. BOF polymers were prepared by varying the weight ratio of BOF to DGEBA and mixing with a stoichiometric quantity of a curing agent. To define polymer networks being discussed in this work, $\mathrm{W}_{\text {epoxy }}$ represents the weight fraction of $\mathrm{BOF}$ or $\mathrm{BOB}$ monomer blended with DGEBA before the addition of curing agents. For example, a sample of a 3:7 weight ratio of BOF to DGEBA was defined to be $\mathrm{W}_{\mathrm{BOF}}=0.3$. Stoichiometric quantities of curing agent were calculated based on $\mathrm{EEW}=188$ for DGEBA, 120 for BOF, 125 for $\mathrm{BOB}$, and amine hydrogen equivalent weight $(\mathrm{AHEW})=52.5$ for PACM and 45 for EPIKURE W. BOF and BOB samples were prepared with $\mathrm{W}_{\mathrm{BOB}}$ and $\mathrm{W}_{\mathrm{BOF}}$ varying from 0 to 1.

BOF and BOB samples were cast into rubber molds with uniform dimensions of $10 \mathrm{~mm}$ by 40 $\mathrm{mm}$ by $5 \mathrm{~mm}$ and cured. The cure procedure, i.e. cure and post cure temperature and cure time, 
was established basing on differential scanning calorimetry (DSC, TA Instruments Q2000) and near-IR studies. ${ }^{35}$ For example, $\mathrm{W}_{\mathrm{BOF}}>0$ samples with $\mathrm{PACM}$ were cured at $60{ }^{\circ} \mathrm{C}$ and postcured at $160{ }^{\circ} \mathrm{C}$ for 9 hours, whereas $\mathrm{W}_{\mathrm{BOF}}=0$ ones with PACM were cured at $80{ }^{\circ} \mathrm{C}$ and $160{ }^{\circ} \mathrm{C}$ for 9 hours to achieve full-cured polymers. ${ }^{18}$ BOB polymer samples were prepared in a similar fashion. After polymer samples were post cured, they were sanded to uniform dimensions for dynamic mechanical analysis (DMA, TA Instruments 2980).

Full conversion of epoxy and amine groups in BOF and BOB polymer samples was verified using a Thermo Nicolet Nexus 870 N-IR spectrometer. Spectra of post-cured samples were recorded in a range of $4000-8000 \mathrm{~cm}^{-1}$, with $8 \mathrm{~cm}^{-1}$ resolution and 32 scans operated in absorbance mode at RT. ${ }^{35}$

Polymer properties. Thermo-mechanical properties of cured BOF and BOB polymer samples were measured by dynamic mechanical analysis (DMA). DMA was performed with a TA Instruments 2980 in single cantilever geometry. Polymer samples were prepared with approximate dimensions of $38 \mathrm{~mm}$ by $9 \mathrm{~mm}$ by $4.5 \mathrm{~mm}$, and tested at a frequency of $1 \mathrm{~Hz}$ with an amplitude of $15 \mu \mathrm{m}$ and a ramp rate of $2{ }^{\circ} \mathrm{C} / \mathrm{min}$ from $\mathrm{RT}$ to a particular temperature (generally approximately $60{ }^{\circ} \mathrm{C}$ higher than the glass transition temperature $\left(\mathrm{T}_{\mathrm{g}}\right)$ of the sample). Each sample was tested twice and the result of the second run was used to measure $\mathrm{T}_{\mathrm{g}}$ and storage modulus. $\mathrm{T}_{\mathrm{g}}$ was assigned as the temperature corresponding to the peak of loss modulus curve.

\section{RESULTS AND DICUSSION}

Comparison of BOF and $\mathrm{BOB}$ epoxy resins cured with PACM and EPIKURE W. BOF and BOB were characterized using multiple techniques, including epoxy titration (ASTM D 1652-97), GPC, FT-IR, ${ }^{1} \mathrm{H}$ NMR, ${ }^{13} \mathrm{C}$ NMR, Rheometry and MS. The results are presented in 
detail in the Supporting Information. Taking BOF as an example, a single sharp GPC peak at 15.6 minute suggests only one component exists. An experimental EEW (123 g/eq.) very close to the theoretical value (120 g/eq.) from epoxy titration, together with its GPC result, indicates that BOF was successfully prepared. Its chemical structure and purity $(>99 \%)$ were also confirmed using ${ }^{1} \mathrm{H}$ NMR and ${ }^{13} \mathrm{C}$ NMR. Similarly, the purity of BOB used in this study was found to be $>99 \%$.

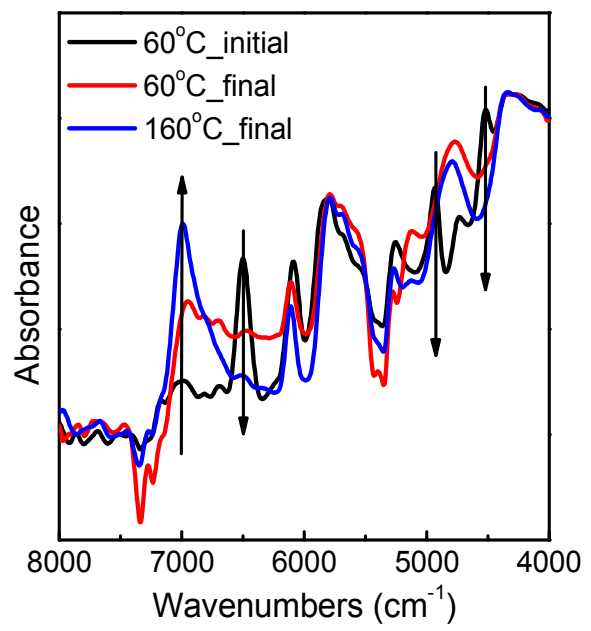

Figure 2. N-IR spectra of a $\mathrm{W}_{\mathrm{BOF}}=1$ sample cured and post-cured with $\mathrm{PACM}$ at $60{ }^{\circ} \mathrm{C}$ and 160 ${ }^{\circ} \mathrm{C}$, respectively.

Full conversion between epoxy and amine groups in BOF and BOB polymer samples was confirmed by N-IR. For example, N-IR spectra of a BOF polymer sample cured with PACM are shown in Figure 2, where black, red and blue curves represented the first scan at $60{ }^{\circ} \mathrm{C}$, the last scan at $60{ }^{\circ} \mathrm{C}$ after 9 hours, and the last scan at $160{ }^{\circ} \mathrm{C}$ for another 9 hours, respectively. It is evident that at $60{ }^{\circ} \mathrm{C}$ the peak corresponding to epoxy groups $\left(4530 \mathrm{~cm}^{-1}\right)$ decreased in conjunction with those corresponding to primary $\left(4935 \mathrm{~cm}^{-1}\right)$ and primary $/$ secondary $\left(6500 \mathrm{~cm}^{-1}\right)$ 
amine groups at $60{ }^{\circ} \mathrm{C}$, while the peak associated with hydroxyl groups $\left(6990 \mathrm{~cm}^{-1}\right)$ formed by the epoxy ring opening reaction increased. After 9 hours at $60{ }^{\circ} \mathrm{C}$, the presence of epoxy and secondary amines is evident while primary amine is not noticeable. This is consistent with known cure behavior of epoxies as primary amines are more reactive than secondary amines. Following post cure at $160{ }^{\circ} \mathrm{C}$ for 9 hours, epoxy, primary and secondary amine peaks are all no longer present, indicating that within the limits of infrared spectroscopy measurements, epoxy and amine groups are fully converted after the cure schedule is completed. These results are representative of all compositions evaluated.
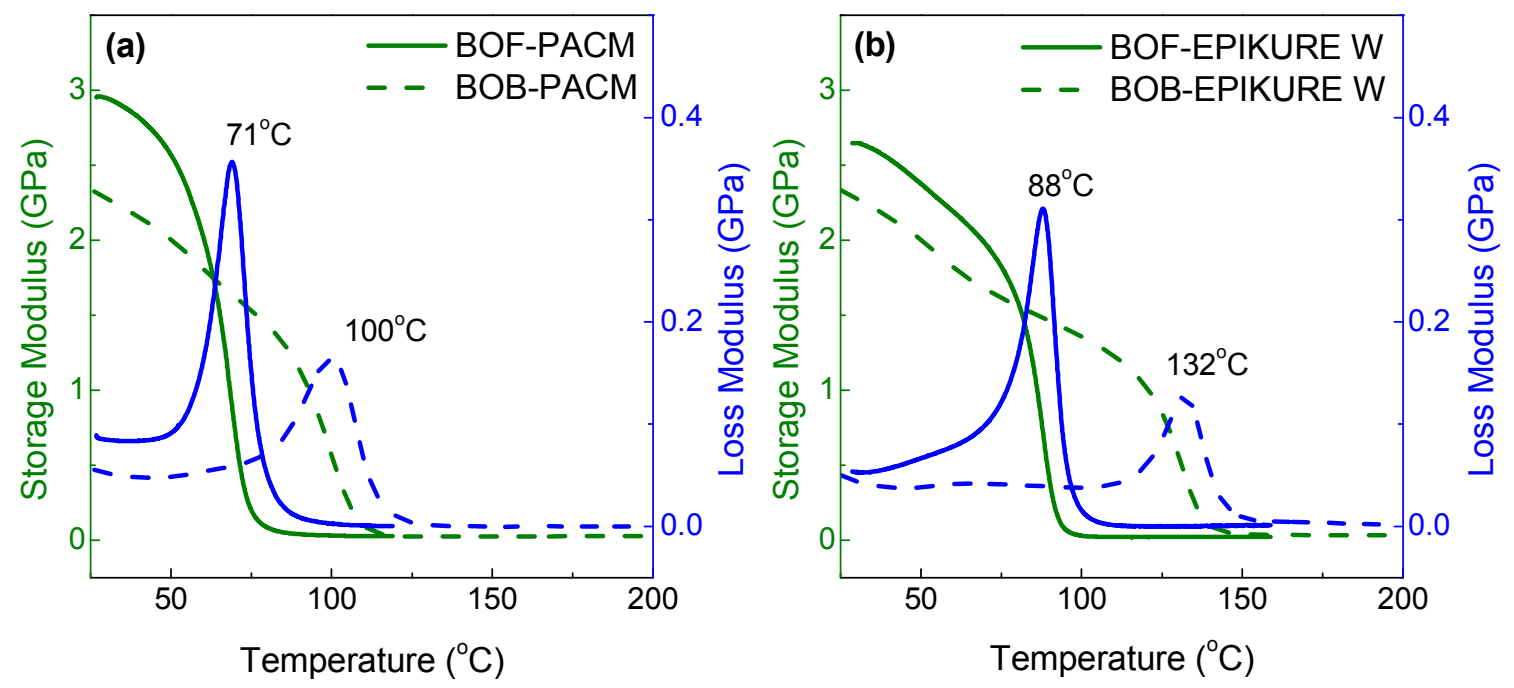

Figure 3. DMA thermograms of cured samples of BOF and BOB with PACM and EPIKURE W, respectively.

The DMA plots of BOF and BOB cured with PACM and EPIKURE W are shown in Figures 3 in which Figure $3 \mathrm{a}$ contains the DMA plots of $\mathrm{BOB}$ and BOF cured with PACM and Figure $3 \mathrm{~b}$ contains those for BOB and BOF cured with EPIKURE W. A sharp loss modulus peak is evident in all cases. On a basis of the peak position for samples cured with PACM, BOF has a $\mathrm{T}_{\mathrm{g}}=71{ }^{\circ} \mathrm{C}$ which is lower higher than the $\mathrm{T}_{\mathrm{g}}$ of $\mathrm{BOB}$ at $100{ }^{\circ} \mathrm{C}$. For samples cured with EPIKURE W, the 
$\mathrm{T}_{\mathrm{g}}$ of BOF is $88^{\circ} \mathrm{C}$ which is also lower than that of BOB at $132^{\circ} \mathrm{C}$. As expected, curing with the aromatic curing agent results in a higher $\mathrm{T}_{\mathrm{g}}$ for both epoxy systems. However, for both the aromatic and cycloaliphatic curing agents $\mathrm{BOF}$ was found to have a lower $\mathrm{T}_{\mathrm{g}}$ than the corresponding BOB epoxy system. The only difference in the chemical structures of these two epoxies is that BOF has a furan ring in place of the benzene ring possessed by BOB. BOF polymer samples possess a higher storage modulus relative to the BOB samples all the way from room temperature through the glass transition for both PACM and EPIKURE W systems. The use of the furan building block increased the stiffness of the cured polymer samples.

One of the potential reasons for the interesting thermo-mechanical behavior of BOF epoxies previously described is that hydrogen bonding occurs between the oxygen atoms of furan rings in BOF and the hydroxyl groups in the epoxy-amine polymer networks generated during epoxy cure. In order to test this hypothesis, M-IR was employed to evaluate hydrogen bonding, as described by others,${ }^{36}$ of BOF monomer and BOF polymer samples cured with PACM and EPIKURE W. The formation of hydrogen bonds can slightly influence bond lengths, energies and electron density distribution of involved chemical bonds, and these changes are normally around two or more orders of magnitude smaller compared with typical chemical changes. IR spectroscopy has the capacity to detect the formation of hydrogen bond at a very sensitive level in this case. M-IR spectra of all three samples are plotted together in Figure 4, where the black curve represents BOF monomer, and red and blue curves correspond to BOF cured with PACM and EPIKURE W, respectively. As expected, a broad peak was present in the region between 3200 to $3500 \mathrm{~cm}^{-1}$, representing hydroxyl groups formed from the epoxy-amine reaction. There are no hydroxyl groups in BOF monomer. Meanwhile, the peak at $1078 \mathrm{~cm}^{-1}$ which corresponds to stretching of $\mathrm{C}-\mathrm{O}-\mathrm{C}$ on furan ring, ${ }^{32}$ in BOF shifted to a lower frequency by $9 \mathrm{~cm}^{-1}$ after 
being cured with PACM and EPIKURE W. It has been suggested ${ }^{36-37}$ that hydrogen bonding can shift the stretch vibration of corresponding functional groups to a lower frequency (red shift), and the value of this red shift is well correlated with the strength of hydrogen bond formed between involved functional groups. However, more evidence is needed to evaluate the significance of hydrogen bonding in affecting thermo-mechanical properties of BOF relative to BOB.
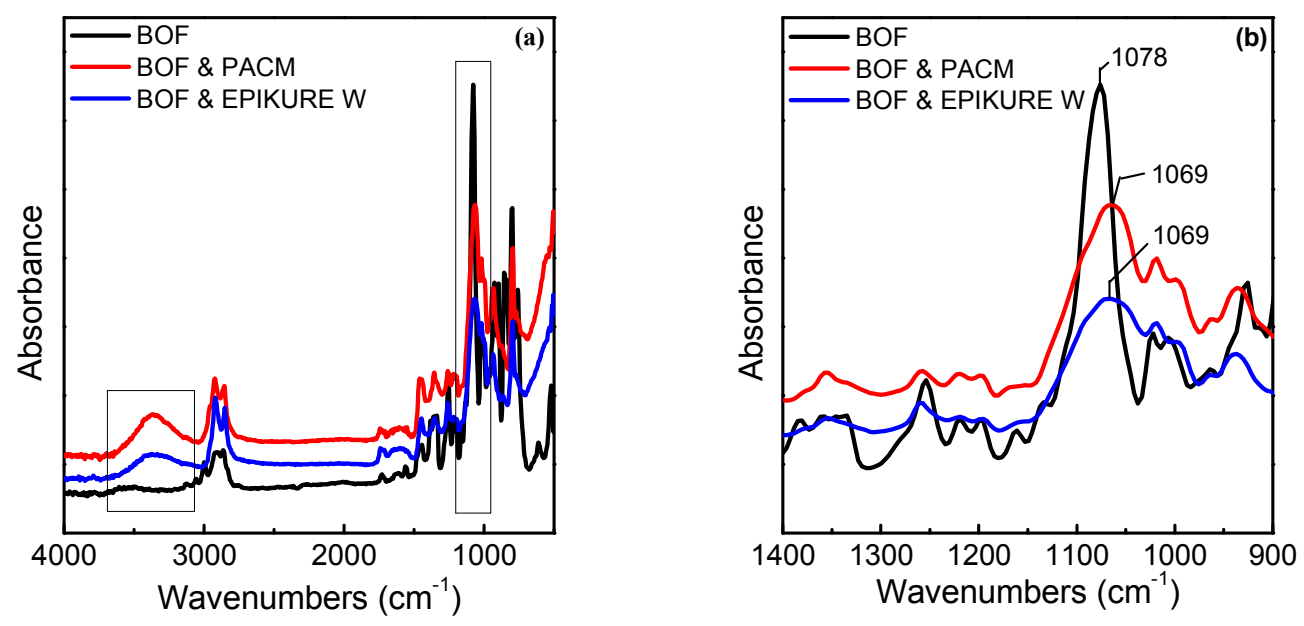

Figure 4. M-IR spectra of BOF and cured BOF polymer samples with PACM and EPIKURE W, respectively. (b) is magnification of (a).

Another explanation for the observed phenomena of thermo-mechanical behavior associated with the furan building block is derived from structural considerations. Even though furan rings in $\mathrm{BOF}$ are asymmetric along the backbone of BOF molecules and rotations around the aromatic unit can theoretically hardly occur, the methylene linkages between furanyl and glycidyloxy groups may facilitate the rotations and allow large scale motion of the chains to occur at lower temperatures. 


\section{Comparison of BOF and BOB polymer samples prepared by blending with DGEBA. In}

order to further explore the differences in properties associating with epoxy networks prepared using furanyl and phenyl building blocks, and to evaluate the viability of using furan based epoxies in conjunction with commercially available resins like DGEBA, polymer samples were prepared by blending with DGEBA at different concentrations. Four sets of polymers were prepared in which the weight fraction of epoxy monomers comprised of DGEBA was varied from $0 \%$ to $100 \%[0 \%, 30 \%, 50 \%, 70 \%$ and $100 \%]$. These sets included: (1) BOF and DGEBA cured stoichiometrically with PACM; (2) BOB and DGEBA cured stoichiometrically with PACM; (3) BOF and DGEBA cured stoichiometrically with EPIKURE W and (4) BOB and DGEBA cured stoichiometrically with EPIKURE W. N-IR was used as discussed previously to ensure complete conversion as measured within the limits of the spectroscopic technique. 

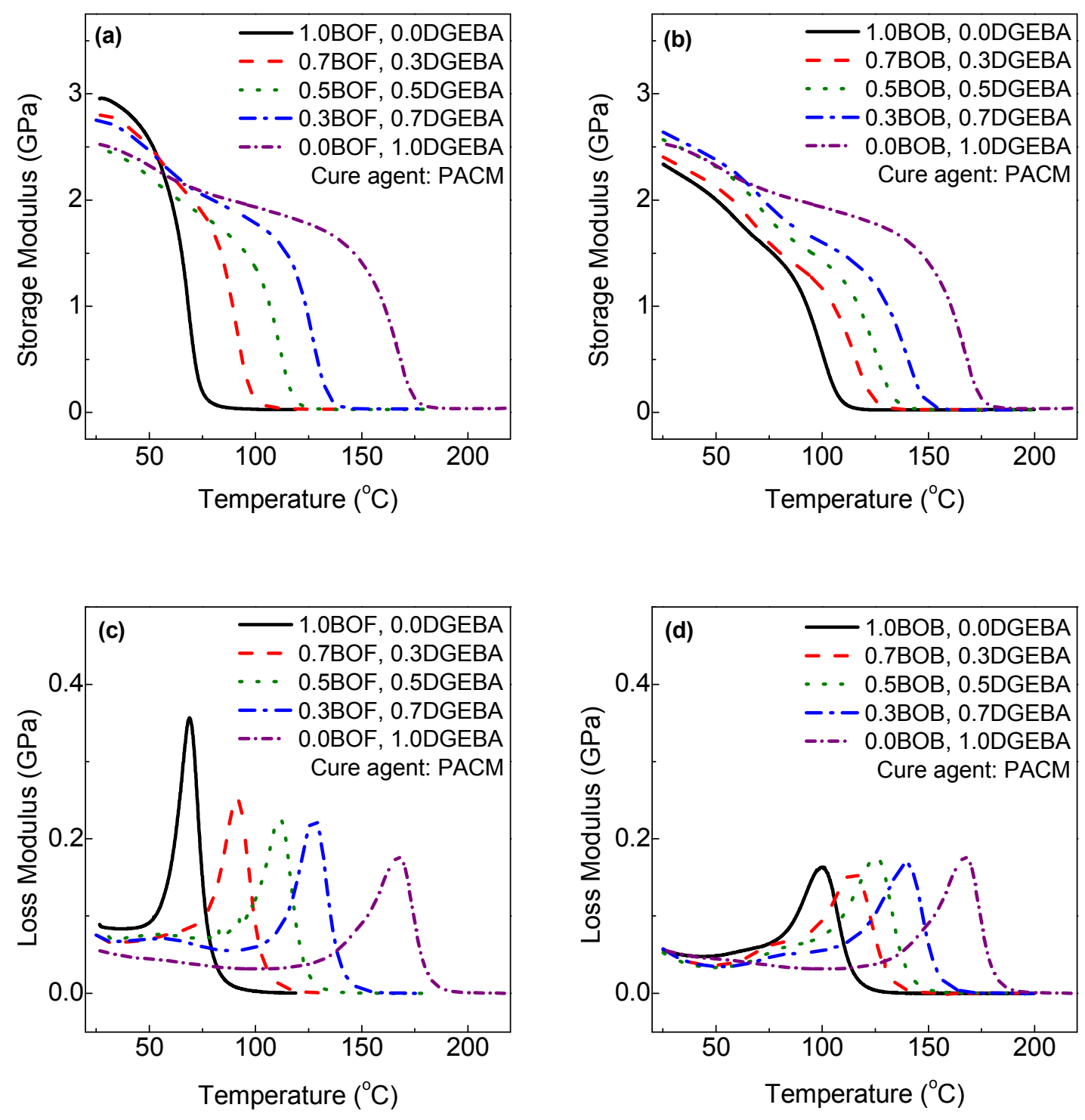

Figure 5. DMA thermograms of cured polymer samples of BOF and BOB blending with DGEBA (EPON 828) at different ratios in PACM system, respectively.

DMA thermograms of BOB- and BOF-based samples cured with PACM are shown in Figure 5, and DMA thermograms of BOB- and BOF-based samples cured with EPIKURE W are given in Figure 6. When blending with DGEBA at different ratios, BOF based samples were found to consistently possess higher storage modulus and lower $\mathrm{T}_{\mathrm{g}}$ compared with BOB-based samples. Figures 5(a) and 5(b) show the storage modulus as a function of temperature of BOF-DGEBA- 
PACM and BOB-DGEBA-PACM samples, respectively. At room temperature, BOF samples show higher storage modulus with increasing BOF content. A similar trend is not observed for BOB containing samples. This result suggests that for samples cured using PACM, furan rings improve polymer glassy modulus even when blending with DGEBA which is not the cases when using BOB. Figure 5(c) and 5(d) show the loss modulus curves for BOF-DGEBA-PACM and BOB-DGEBA-PACM samples respectively. All BOF and BOB samples display a single sharp loss modulus peak, suggesting that phase separation has not occurred in the cured polymer networks. The peak positions of loss modulus curves shift to higher temperatures with increasing DGEBA content. Also, for BOF-DGEBA-PACM samples, the height of the loss modulus peak decreases with increasing content of DGEBA, and the area under the loss modulus-temperature curve in the vicinity of glass transition temperature decreases with increasing content of DGEBA. For BOB-DGEBA-PACM samples, the loss modulus peak height and the area under the loss modulus-temperature curve remains similar when increasing the DGEBA content. 

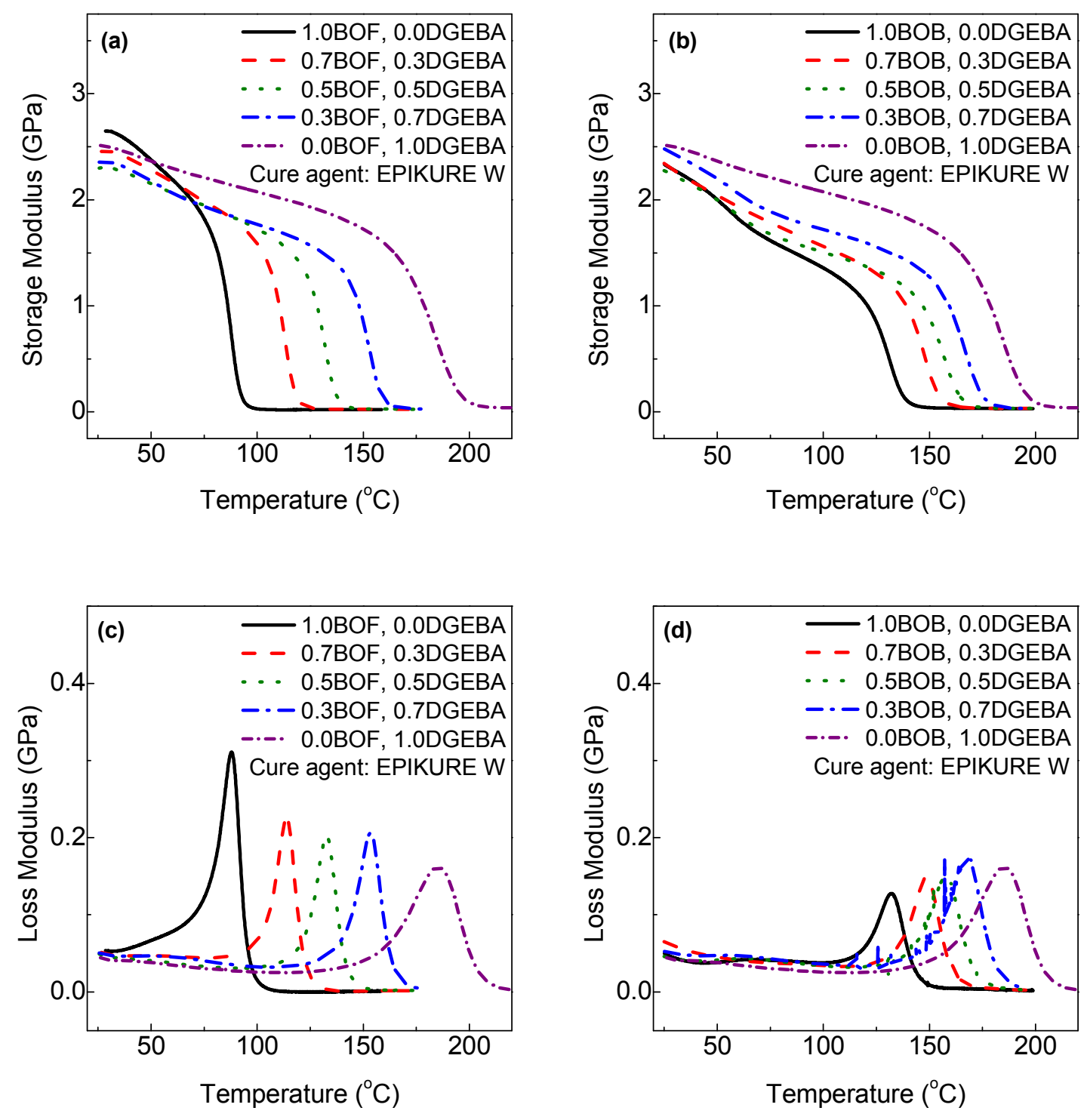

Figure 6. DMA thermograms of cured polymer samples of BOF and BOB blending with DGEBA (EPON 828) at different ratios in EPIKURE W system, respectively.

For BOB-DGEBA-PACM samples, the loss modulus peak height and the area under the loss modulus-temperature curve remains similar when increasing the DGEBA content. DMA thermograms of BOB and BOF samples cured with EPIKURE W are shown in Figure 6. Figures 6(a) and 6(b) show the storage modulus as a function of temperature of BOF-DGEBA-EPIKURE $\mathrm{W}$ and BOB-DGEBA-EPIKURE $\mathrm{W}$ samples, respectively. At room temperature, the storage 
moduli of BOF-DGEBA-EPIKURE $\mathrm{W}$ samples did not follow the trend observed for the systems cured with PACM since the addition of BOF produced modulus similar to those of pure BOF and DGEBA cured with EPIKURE W, respectively. The same behavior was observed for the set of BOB polymers. The loss modulus curves given in Figures 6(c) and 6(d) for BOF-DGEBAEPIKURE $\mathrm{W}$ and BOB-DGEBA-EPIKURE $\mathrm{W}$ samples show that the systems cured with EPIKURE W behave very similarly to those cured with PACM. BOF and BOB samples display a single sharp loss modulus peak, suggesting that phase separation has not occurred, and the height of the loss modulus peak decreases with increasing contents of DGEBA and the peak positions of the loss modulus curves shift to higher temperatures with increasing DGEBA content in BOF-DGEBA-EPIKURE W samples.

Table 2. $T_{\mathrm{g}}$ data of BOF/BOB - DGEBA cured with PACM/EPIKURE $W$ at stoichiometry

\begin{tabular}{ccccc}
\hline & \multicolumn{4}{c}{$\mathrm{T}_{\mathrm{g}}\left({ }^{\circ} \mathrm{C}\right)$ by DMA $^{a}$} \\
$\begin{array}{c}\text { Weight ratio of } \\
\text { epoxy monomers }\end{array}$ & BOF- & BOB- & BOF- & BOB- \\
(BOF/BOB:DGEBA) & DGEBA & DGEBA & DGEBA & DGEBA \\
\hline 100:0 & $\mathbf{7 1 ~ ( 8 0 )}$ & $\mathbf{1 0 0}(\mathbf{1 1 1})$ & $\mathbf{8 8 ~ ( 9 4 )}$ & $\mathbf{1 3 2}(\mathbf{1 4 0})$ \\
$70: 30$ & $96(106)$ & $115(126)$ & $114(120)$ & $148(156)$ \\
$50: 50$ & $111(121)$ & $125(136)$ & $133(139)$ & $158(166)$ \\
$30: 70$ & $131(140)$ & $140(150)$ & $153(160)$ & $168(177)$ \\
$0: 100$ & $167(176)$ & $167(176)$ & $185(198)$ & $185(198)$ \\
\hline
\end{tabular}

${ }^{a} \mathrm{~T}_{\mathrm{g}}$ assigned as the temperature at the peak position of loss modulus curve from DMA. Values in parentheses were $\mathrm{T}_{\mathrm{g}}$ assigned as the temperature at the maximum of $\tan \delta$ curve from DMA.

$\mathrm{T}_{\mathrm{g}}$ for the four sets of polymer samples was obtained using the peak position of the loss modulus curves found in Figures 5 and 6 . The $\mathrm{T}_{\mathrm{g}}$ values are summarized in Table 2. All samples tested presented a single sharp $\mathrm{T}_{\mathrm{g}}$. A single composition-dependent glass transition is frequently considered as an indication of miscibility on an order of $20-40 \mathrm{~nm} .{ }^{38}$ We conclude that BOF and BOB are well miscible with DGEBA. As shown in Table 2, BOF always possesses a lower $\mathrm{T}_{\mathrm{g}}$ 
than its phenyl analog when cured with both aromatic and cycloaliphatic curing agents and also when blended with DGEBA. Based on previous discussions, this likely occurs because the methylene linkages between furanyl and glycidyloxy groups in BOF facilitate the rotations and allow large scale motion of the chains to occur at lower temperatures, even though furan rings in BOF are able to form hydrogen bonds and are not symmetrical, compared to benzene rings in BOB. Polymer samples with EPIKURE $W$ generally possessed higher $T_{g}$ than those with PACM in both $\mathrm{BOF}$ and $\mathrm{BOB}$ systems, because EPIKURE W with aromatic ring structures are more thermally rigid than PACM with cycloaliphatic ring structures ${ }^{39}$. Furthermore, the difference of $\mathrm{T}_{\mathrm{g}}$ between BOF and BOB samples was found to decrease with increasing DGEBA content.

$\mathrm{T}_{\mathrm{g}}$ increased greatly with decreasing content of BOF and $\mathrm{BOB}$ in PACM and EPIKURE W systems. The $\mathrm{T}_{\mathrm{g}}$ differences between BOB-PACM $\left(100^{\circ} \mathrm{C}\right)$ and DGEBA-PACM $\left(167{ }^{\circ} \mathrm{C}\right)$, as well as between BOB-EPIKURE $\mathrm{W}\left(132^{\circ} \mathrm{C}\right)$ and DGEBA-EPIKURE $\mathrm{W}\left(185^{\circ} \mathrm{C}\right)$ are $67^{\circ} \mathrm{C}$ and $53{ }^{\circ} \mathrm{C}$, respectively. By comparing chemical structures between BOF/BOB and DGEBA (Figure 1), an obvious difference is that DGEBA does not possess methylene groups between phenyl and glycidyloxy groups that are found in both BOF and BOB. These additional methylene groups potentially decrease $\mathrm{T}_{\mathrm{g}}$ of $\mathrm{BOF}$ and $\mathrm{BOB}$ polymers since furanyl or phenyl segments attached to them are less constrained. In order to test this reasoning, DGEPP whose structure is given in Figure 1 was cured using EPIKURE W at stoichiometry. DGEPP was mixed with EPIKURE W at $110{ }^{\circ} \mathrm{C}$, which is the melting point of DGEPP, and poured into silicone molds. Cure was conducted at $140{ }^{\circ} \mathrm{C}$ for 9 hours and postcured at $240{ }^{\circ} \mathrm{C}$ for 3 hours. DGEPP structurally differs from $\mathrm{BOB}$ in that it lacks the methylene groups. Thermo-mechanical properties were measured using DMA with a temperature rate of $2{ }^{\circ} \mathrm{C} / \mathrm{min}$ from $\mathrm{RT}$ to $320{ }^{\circ} \mathrm{C}$ and results are plotted in Figure 7 with those of DGEBA cured with EPIKURE W for comparison. A $\mathrm{T}_{\mathrm{g}}$ of $193{ }^{\circ} \mathrm{C}$ was 
obtained for the DGEPP system which is slightly higher than that of DGEBA. More interesting is that the $\mathrm{T}_{\mathrm{g}}$ of DGEPP-EPIKURE $\mathrm{W}$ is $61{ }^{\circ} \mathrm{C}$ higher than that of BOB-EPIKURE $\mathrm{W}$. So we conclude that the additional methylene linkages are responsible for the much lower $\mathrm{T}_{\mathrm{g}}$ of $\mathrm{BOF}$ and BOB systems compared to DGEBA.

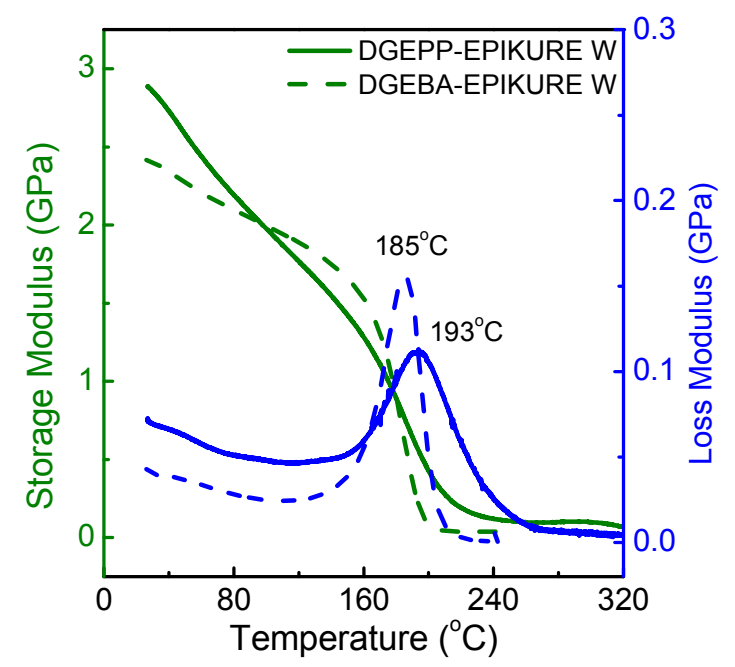

Figure 7. DMA thermograms of cured samples of DGEPP and DGEBA with EPIKURE W, respectively.

The Fox Equation (Equation 1) was employed to fit experimental $T_{g}$ data reported in Table 2, and serves the purpose of describing $T_{g}$ of the multicomponent networks as a function of relative epoxy monomer content.

$$
\frac{1}{T_{g}}=\frac{w_{1}}{T_{g, 1}}+\frac{w_{2}}{T_{g, 2}}
$$

In this equation $\mathrm{w}_{1}$ and $\mathrm{w}_{2}$ represent weight fractions of components 1 and $2, \mathrm{~T}_{\mathrm{g}, 1}$ and $\mathrm{T}_{\mathrm{g}, 2}$ are $\mathrm{T}_{\mathrm{g}}$ values of polymer samples containing only components 1 and 2 , respectively. For example, in 
the case of BOF-DGEBA-PACM system, component 1 is BOF/PACM and component 2 is DGEBA/PACM.

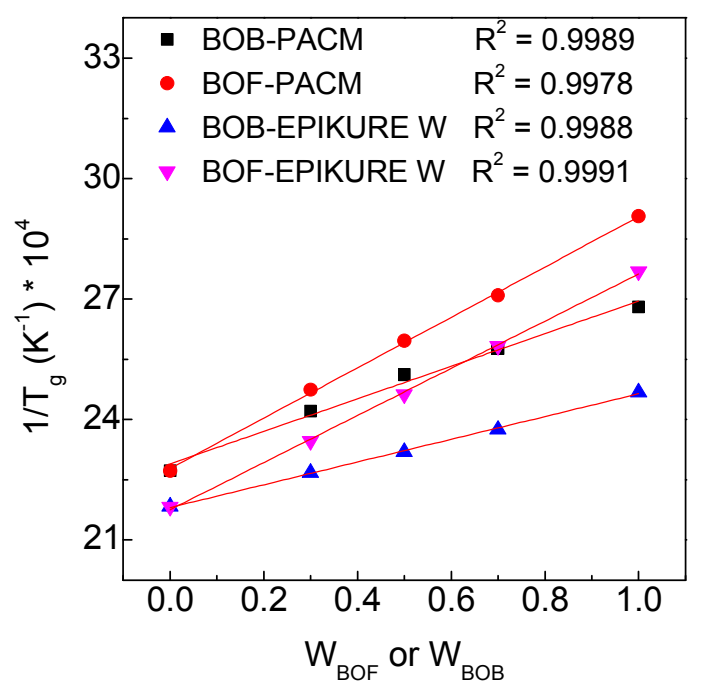

Figure 8. Relationship between $1 / \mathrm{T}_{\mathrm{g}}$ and $\mathrm{W}_{\mathrm{BOF}}$ or $\mathrm{W}_{\mathrm{BOB}}$.

Figure 8 is a plot of $\mathrm{W}_{\mathrm{BOF}}$ or $\mathrm{W}_{\mathrm{BOB}}$ versus the reciprocal of $\mathrm{T}_{\mathrm{g}}$ for the four sets of polymers being discussed. Also plotted in Figure 8 are the best-fit lines corresponding to the Fox Equation for each set of data. All four groups of polymer samples show excellent agreement $\left(\mathrm{R}^{2}>0.997\right)$ with the Fox Equation. This further indicates that BOF and BOB both possess good miscibility with DGEBA implying the polymer networks are homogeneous ${ }^{34,40}$.

\section{CONCLUSIONS}

1, 4-bis[(2-oxiranylmethoxy)methyl]-Furan (BOF) and its benzene analog, 1, 4-bis[(2oxiranylmethoxy)methyl]-Benzene (BOB), were successfully synthesized. BOF and BOB are both liquids with low viscosity and good processability. After being fully cured with standard cycloaliphatic (PACM) and aromatic (EPIKURE W) curing agents, BOF-based epoxy-amine thermoset polymers were found to possess a lower $\mathrm{T}_{\mathrm{g}}$ and a higher storage modulus than BOB systems. Possible reasons for this are the methylene linkages between furanyl and glycidyloxy 
groups in $\mathrm{BOF}$ that facilitate rotation of the five-membered furan ring and the possibility of enhanced hydrogen bonding between the oxygen atoms in the furan rings and hydroxyl groups created by the epoxy ring opening reaction with amine curing agents. Furthermore, it was found that the additional methylene linkages between the aromatic ring and the glycidyloxy group in BOF and BOB lead to much lower $\mathrm{T}_{\mathrm{g}}$ than thermosets made with phenolic glycidyl ethers like DGEBA and DGEPP that do not have them. BOF shows excellent miscibility with DGEBA resulting in the formation of homogenous network that follows the Fox Equation with high fidelity. These results suggest that the furan ring, which is available from many biomass sources, is a viable substitute for incumbent petroleum-based thermosetting resins that use benzene as a building block.

\section{ASSOCIATED CONTENT}

\section{Supporting Information}

Additional characterization data, such as GPC characterization, epoxy equivalent weight

measurement, ${ }^{1} \mathrm{H}$ NMR and ${ }^{13} \mathrm{C}$ NMR as well as N-IR and M-IR spectra, of BOF and BOB. This material is available free of charge via the Internet at http://pubs.acs.org.

\section{AUTHOR INFORMATION}

\section{Corresponding Author}

*E-mail: grp27@drexel.edu

\section{ACKNOWLEDGMENTS}

The authors acknowledge financial support from SERDP under Project WP03-015 as well as from the U.S. Army Research Laboratory under the Army Materials Center of Excellence Program, contract W911NF-06-2-0013. Support from the China Scholarship Council is also 
acknowledged. The authors wish to thank the Department of Chemistry at Drexel University for use of ${ }^{1} \mathrm{H}$ NMR, ${ }^{13} \mathrm{C}$ NMR and MS facilities.

\section{REFERENCES}

1. McCrum, N. G.; Buckley, C. P.; Bucknall, C. B., Principles of polymer engineering. Oxford University Press.: New York, 1997.

2. (a) Raquez, J. M.; Deleglise, M.; Lacrampe, M. F.; Krawczak, P., Thermosetting (bio)materials derived from renewable resources: A critical review. Progress in Polymer Science 2010, 35 (4), 487-509; (b) Hussain, F.; Hojjati, M.; Okamoto, M.; Gorga, R. E., Review article: Polymer-matrix nanocomposites, processing, manufacturing, and application: An overview. $J$ Compos Mater 2006, 40 (17), 1511-1575.

3. (a) Painter, P. C.; Coleman, M. M., Fundamentals of polymer science: an introductory text. Technomic Pub. Co.: Lancaster, Pa., 1997; (b) Ellis, B., Chemistry and Technology of Epoxy Resins. Blackie: New York, 1992; (c) May, C. A., Epoxy Resins: Chemistry and Technology. 2nd ed.; Marcel Dekker: New York, 1988; (d) Zheng, S.; Pascault, J.; Williams, R., Epoxy polymers: new materials and innovations. Pascault, JP, Williams, RJJ, Eds 2010.

4. (a) Meier, M. A. R.; Metzger, J. O.; Schubert, U. S., Plant oil renewable resources as green alternatives in polymer science. Chem Soc Rev 2007, 36 (11), 1788-1802; (b) Auvergne, R.; Caillol, S.; David, G.; Boutevin, B.; Pascault, J.-P., Biobased Thermosetting Epoxy: Present and Future. Chemical reviews 2014.

5. (a) Mülhaupt, R., Green Polymer Chemistry and Bio-based Plastics: Dreams and Reality. Macromolecular Chemistry and Physics 2013, 214 (2), 159-174; (b) Mathers, R. T., How well can renewable resources mimic commodity monomers and polymers? Journal of Polymer Science Part A: Polymer Chemistry 2012, 50 (1), 1-15.

6. (a) Lacerda, T. M.; Gandini, A., Marriage of Furans and Vegetable Oils through Click Chemistry for the Preparation of Macromolecular Materials: A Succinct Review. Journal of Renewable Materials 2013, 1-11; (b) Montero de Espinosa, L.; Meier, M. A., Plant oils: The perfect renewable resource for polymer science?! European Polymer Journal 2011, 47 (5), 837852.

7. Wool, R.; Sun, X. S., Bio-based polymers and composites. Academic Press: 2011.

8. Belgacem, M. N.; Gandini, A., Monomers, polymers and composites from renewable resources. 1st ed.; Elsevier: Amsterdam: Boston, 2008; p 1.

9. Guigo, N.; Mija, A.; Vincent, L.; Sbirrazzuoli, N., Eco-friendly composite resins based on renewable biomass resources: Polyfurfuryl alcohol/lignin thermosets. European Polymer Journal 2010, 46 (5), 1016-1023.

10. Elchinger, P.-H.; Montplaisir, D.; Zerrouki, R., Starch-cellulose crosslinking-Towards a new material. Carbohydrate Polymers 2012, 87 (2), 1886-1890.

11. (a) Kasaai, M. R., A review of several reported procedures to determine the degree of $\mathrm{N}$ acetylation for chitin and chitosan using infrared spectroscopy. Carbohydrate Polymers 2008, 71 (4), 497-508; (b) Ravi Kumar, M. N., A review of chitin and chitosan applications. Reactive and functional polymers 2000, 46 (1), 1-27.

12. (a) Czub, P., Synthesis of high-molecular-weight epoxy resins from modified natural oils and Bisphenol A or BisphenolA-based epoxy resins. Polymers for Advanced Technologies 2009, 20 (3), 194-208; (b) Lligadas, G.; Ronda, J. C.; Galià, M.; Cádiz, V., Development of novel 
phosphorus-containing epoxy resins from renewable resources. Journal of Polymer Science Part A: Polymer Chemistry 2006, 44 (23), 6717-6727.

13. Łukaszczyk, J.; Janicki, B.; Kaczmarek, M., Synthesis and properties of isosorbide based epoxy resin. European Polymer Journal 2011, 47 (8), 1601-1606.

14. (a) Holladay, J. E.; White, J. F.; Bozell, J. J.; Johnson, D. Top Value-Added Chemicals from Biomass - Volume II-Results of Screening for Potential Candidates from Biorefinery Lignin; U.S. Department of Energy, Technical Report Office of Scientific and Technical Information, NREL: Oak Ridge, TN, 2007; (b) Tuck, C. O.; Pérez, E.; Horváth, I. T.; Sheldon, R. A.; Poliakoff, M., Valorization of biomass: deriving more value from waste. Science 2012, 337 (6095), 695-699.

15. (a) Cho, J. K.; Lee, J.-S.; Jeong, J.; Kim, B.; Kim, B.; Kim, S.; Shin, S.; Kim, H.-J.; Lee, S.-H., Synthesis of carbohydrate biomass-based furanic compounds bearing epoxide end group (s) and evaluation of their feasibility as adhesives. Journal of Adhesion Science and Technology 2013, 27 (18-19), 2127-2138; (b) Jeong, J.; Kim, B.; Shin, S.; Kim, B.; Lee, J.-S.; Lee, S.-H.; Cho, J. K., Synthesis and photo-polymerization of bio-based furanic compounds functionalized by 2-hydroxypropyl methacrylate group(s). J Appl Polym Sci 2013, 127 (4), 2483-2489; (c) Gandini, A.; Belgacem, M. N., Furans in polymer chemistry. Progress in Polymer Science 1997, 22 (6), 1203-1379.

16. (a) Peterson, A. M.; Jensen, R. E.; Palmese, G. R., Reversibly Cross-Linked Polymer Gels as Healing Agents for Epoxy- Amine Thermosets. Acs Appl Mater Inter 2009, 1 (5), 992995; (b) Peterson, A. M.; Palmese, G. R., Reaction Kinetics and Thermodynamic Aspects of Thermoreversibly Cross - Linked Polymer Networks. Macromolecular Chemistry and Physics 2013, 214 (16), 1798-1805.

17. (a) Pratama, P. A.; Peterson, A. M.; Palmese, G. R., Diffusion and Reaction Phenomena in Solution - Based Healing of Polymer Coatings Using the Diels-Alder Reaction.

Macromolecular Chemistry and Physics 2012, 213 (2), 173-181; (b) Peterson, A. M.; Jensen, R. E.; Palmese, G. R., Kinetic Considerations for Strength Recovery at the Fiber-Matrix Interface Based on the Diels-Alder Reaction. Acs Appl Mater Inter 2013, 5 (3), 815-821.

18. Palmese, G. R.; Mccullough, R. L., Effect of Epoxy Amine Stoichiometry on Cured Resin Material Properties. J Appl Polym Sci 1992, 46 (10), 1863-1873.

19. (a) Espinoza - Perez, J. D.; Nerenz, B. A.; Haagenson, D. M.; Chen, Z.; Ulven, C. A.; Wiesenborn, D. P., Comparison of curing agents for epoxidized vegetable oils applied to composites. Polymer Composites 2011, 32 (11), 1806-1816; (b) Knorr Jr, D. B.; Yu, J. H.; Richardson, A. D.; Hindenlang, M. D.; McAninch, I. M.; La Scala, J. J.; Lenhart, J. L., Glass transition dependence of ultrahigh strain rate response in amine cured epoxy resins. Polymer 2012, 53 (25), 5917-5923.

20. (a) Guo, Q., Thermosets: Structure, properties and applications. Elsevier: 2012; (b) Schäfer, A.; Seibold, S.; Walter, O.; Döring, M., Novel high Tg flame retardancy approach for epoxy resins. Polymer Degradation and Stability 2008, 93 (2), 557-560.

21. Nouailhas, H.; Aouf, C.; Le Guerneve, C.; Caillol, S.; Boutevin, B.; Fulcrand, H., Synthesis and properties of biobased epoxy resins. part 1. Glycidylation of flavonoids by epichlorohydrin. Journal of Polymer Science Part A: Polymer Chemistry 2011, 49 (10), 22612270 .

22. Aouf, C.; Nouailhas, H.; Fache, M.; Caillol, S.; Boutevin, B.; Fulcrand, H., Multifunctionalization of gallic acid. Synthesis of a novel bio-based epoxy resin. European Polymer Journal 2013, 49 (6), 1185-1195. 
23. (a) Ochi, M.; Shimbo, M.; Saga, M.; Takashima, N., Mechanical and dielectric relaxations of epoxide resins containing spiro - ring structure. Journal of Polymer Science Part B: Polymer Physics 1986, 24 (10), 2185-2195; (b) Ochi, M.; Shiba, T.; Takeuchi, H.; Yoshizumi, M.; Shimbo, M., Effect of the introduction of methoxy branches on low-temperature relaxations and fracture toughness of epoxide resins. Polymer 1989, 30 (6), 1079-1084.

24. Sachinvala, N. D.; Winsor, D. L.; Menescal, R. K.; Ganjian, I.; Niemczura, W. P.; Litt, M. H., Sucrose-based epoxy monomers and their reactions with diethylenetriamine. Journal of Polymer Science Part A: Polymer Chemistry 1998, 36 (13), 2397-2413.

25. East, A.; Jaffe, M.; Zhang, Y.; Catalani, L. H. Thermoset epoxy polymers from renewable resources; Iowa Corn Promotion Board: 2009.

26. (a) Chrysanthos, M.; Galy, J.; Pascault, J.-P., Preparation and properties of bio-based epoxy networks derived from isosorbide diglycidyl ether. Polymer 2011, 52 (16), 3611-3620; (b) Chrysanthos, M.; Galy, J.; Pascault, J. P., Influence of the Bio - Based Epoxy Prepolymer Structure on Network Properties. Macromolecular Materials and Engineering 2013, 298 (11), 1209-1219.

27. Earls, J. D.; White, J. E.; López, L. C.; Lysenko, Z.; Dettloff, M. L.; Null, M. J., Aminecured $\omega$-epoxy fatty acid triglycerides: Fundamental structure-property relationships. Polymer 2007, 48 (3), 712-719.

28. Koike, T., Progress in development of epoxy resin systems based on wood biomass in Japan. Polymer Engineering \& Science 2012, 52 (4), 701-717.

29. Fenouillot, F.; Rousseau, A.; Colomines, G.; Saint-Loup, R.; Pascault, J.-P., Polymers from renewable 1, 4: 3, 6-dianhydrohexitols (isosorbide, isomannide and isoidide): A review. Progress in Polymer Science 2010, 35 (5), 578-622.

30. Morgan, R. J.; Kong, F.-M.; Walkup, C. M., Structure-property relations of polyethertriamine-cured bisphenol-A-diglycidyl ether epoxies. Polymer 1984, 25 (3), 375-386.

31. (a) Tsujigami, T.; Sugai, T.; Ohta, H., Microbial asymmetric reduction of alphahydroxyketones in the anti-Prelog selectivity. Tetrahedron-Asymmetr 2001, 12 (18), 2543-2549; (b) Sun, F. L.; Xu, G.; Wu, H. P.; Yang, L. R., Efficient lipase-catalyzed kinetic resolution of 4arylmethoxy-3-hydroxybutanenitriles: application to an expedient synthesis of a statin intermediate. Tetrahedron-Asymmetr 2006, 17 (20), 2907-2913.

32. Tian, Q.; Rong, M. Z.; Zhang, M. Q.; Yuan, Y. C., Synthesis and characterization of epoxy with improved thermal remendability based on Diels-Alder reaction. Polymer International 2010, 59 (10), 1339-1345.

33. ASTM D1652-90, Standard Test Methods for Epoxy Content of Epoxy Resins. ASTM International: West Conshohocken, PA, 2003; p 3.

34. Peterson, A. M.; Jensen, R. E.; Palmese, G. R., Room-Temperature Healing of a Thermosetting Polymer Using the Diels-Alder Reaction. Acs Appl Mater Inter 2010, 2 (4), 1141 1149.

35. McAninch, I. M.; Palmese, G. R.; Lenhart, J. L.; La Scala, J. J., Characterization of epoxies cured with bimodal blends of polyetheramines. J Appl Polym Sci 2013, 130 (3), 1621 1631.

36. (a) He, Y.; Zhu, B.; Inoue, Y., Hydrogen bonds in polymer blends. Progress in Polymer Science 2004, 29 (10), 1021-1051; (b) Su, Y.-C.; Kuo, S.-W.; Yei, D.-R.; Xu, H.; Chang, F.-C., Thermal properties and hydrogen bonding in polymer blend of polybenzoxazine/poly $(N$-vinyl-2pyrrolidone). Polymer 2003, 44 (8), 2187-2191. 
37. (a) He, Y.; Asakawa, N.; Inoue, Y., Studies on poly ( $\varepsilon$ - caprolactone)/thiodiphenol blends: The specific interaction and the thermal and dynamic mechanical properties. Journal of Polymer Science Part B: Polymer Physics 2000, 38 (14), 1848-1859; (b) Liu, Y.; Goh, S.; Lee, S.; Huan, C., Miscibility and Interactions in Blends and Complexes of Poly (N-acryloyl-N'methylpiperazine) with Poly (p-vinylphenol). Macromolecules 1999, 32 (6), 1967-1971; (c) Chen, N.; Hong, L., Surface phase morphology and composition of the casting films of PVDFPVP blend. Polymer 2002, 43 (4), 1429-1436; (d) Iriondo, P.; Iruin, J.; Fernandez-Berridi, M., Thermal and infra-red spectroscopic investigations of a miscible blend composed of poly (vinyl phenol) and poly (hydroxybutyrate). Polymer 1995, 36 (16), 3235-3237.

38. Duan, Y.; Pearce, E. M.; Kwei, T.; Hu, X.; Rafailovich, M.; Sokolov, J.; Zhou, K.; Schwarz, S., Surface enrichment in polymer blends involving hydrogen bonding. Macromolecules 2001, 34 (19), 6761-6767.

39. (a) Bellenger, V.; Verdu, J.; Morel, E., Effect of Structure on Glass-Transition Temperature of Amine Cross-Linked Epoxies. J Polym Sci Pol Phys 1987, 25 (6), 1219-1234; (b) Pascault, J. P.; Sautereau, H.; Verdu, J.; Williams, R. J. J., Thermosetting polymers. CRC: 2002; Vol. 64.

40. Sheng, X.; Kessler, M.; Lee, J., The influence of cross-linking agents on ring-opening metathesis polymerized thermosets. Journal of thermal analysis and calorimetry 2007, 89 (2), 459-464. 
For Table of Contents use only

\section{Correction to Synthesis and Characterization of Thermosetting Furan-Based Epoxy Systems}

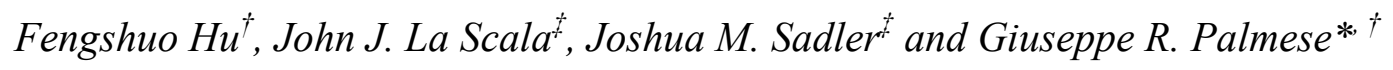

$\dagger$ Department of Chemical \& Biological Engineering, Drexel University, Philadelphia, PA 19104, USA

${ }^{\ddagger}$ Army Research Labs, 4600 Deer Creek Loop, Aberdeen Proving Grounds, MD 21005-5069, USA

Macromolecules, 2014, 47 (10), 3332-3342. DOI: 10.1021/ma500687t
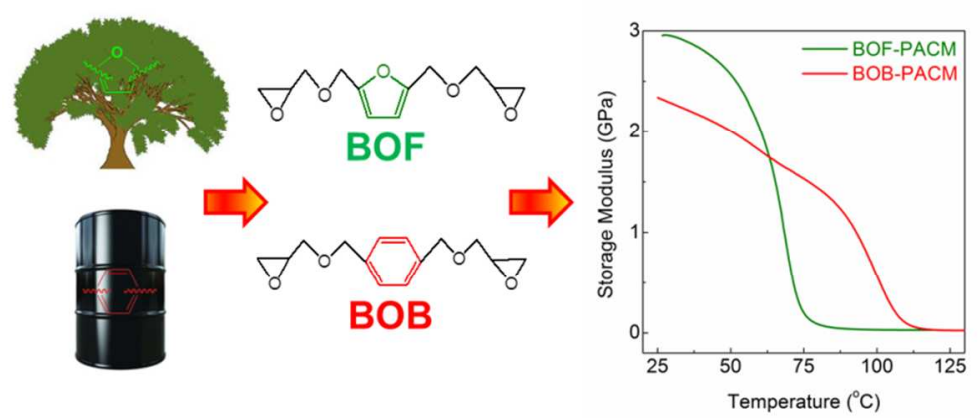